\title{
Detection of Pesticide Residues in Organic and Conventional Fruits and Vegetables Available in Ireland Using Gas Chromotography/Tandem Mass Spectrometry (GC-MS/MS) and Liquid Chromotography/Tandem Mass Spectrometry (LC-MS/MS) Detection
}

\author{
Rachel Tobin ${ }^{1 *}$, Tony Walsh ${ }^{2}$, Jim Garvey ${ }^{2}$ and Tracey Larkin ${ }^{1}$ \\ ${ }^{1}$ Department of Applied Science/Shannon Applied Biotechnology Centre, Limerick Institute of Technology, Ireland \\ ${ }^{2}$ Department of Agriculture, Food and Marine Pesticide Regulation and Control Division, Backweston Laboratory Campus, Ireland
}

Received: January 20, 2014; Accepted: February 10, 2014; Published: February 13, 2014

*Corresponding author: Rachel Tobin, Department of Applied Science/Shannon Applied Biotechnology Centre, Limerick Institute of Technology, Moylish Park, Limerick, Ireland, E-mail: Rachel.Tobin@lit.ie

\begin{abstract}
Irish organic consumers believe that organic foods are a healthier choice due to the lack of synthetic pesticides used in organic agricultural practices; however, few scientific studies have shown that organic samples are void of any pesticide residues. Nine different fruit and vegetable types of organic and conventional origin were sampled from large supermarkets. Analysis for 465 pesticide residues was carried out using GC-MS/MS and LC-MS/MS analysis. Of the 27 organic samples tested, 15 contained one or more detected pesticide residues, with one of these being above the limit of quantification (LOQ) for the method, imazalil in organic onion, 11.13 $\mathrm{ng} / \mathrm{g}$. Of the conventional samples 17 of the 27 samples contained one or more residues. Twelve of the residues detected in conventional samples were above the $\mathrm{LOQ}$ with concentrations ranging from 9.84 to $154.10 \mathrm{ng} / \mathrm{g}$. A similar number of organic (15) and conventional (17) samples tested positive for detectable residues, however the number of residues detected was higher in conventional (43) than in organic (29), and the concentration of these residues were higher. It is concluded that it cannot be said that organic fruits and vegetables are void of pesticides based on the results of this study.
\end{abstract}

Keywords: Organic; Fruits; Vegetables; Pesticides; GCMS; LCMS

\section{Introduction}

Pesticides are chemical, biocidal products that are used for the control of organisms that effect plant, human or animal health, in particular when the organisms cause damage to natural or manufactured products e.g. food crops. Pesticides fall in to three main categories; fungicides, herbicides and insecticides, based on their target action [1]. Most pesticides are toxic to humans on some level and the World Health Organisation (WHO) has classified these effects from Ia- Extremely hazardous to UUnlikely to present acute hazard based on the $\mathrm{LD}_{50}$ (lethal dose required to kill $50 \%$ of a test animal population) for the rat $\mathrm{mg} /$ Kg body weight [2].
Organic agricultural practices are distinguishable from nonorganic or conventional practices mainly by their non-use of soluble minerals for soil fertilization and pesticides for plant protection and growth. The use of such substances is strictly prohibited under organic certification standards. The Codex Alimentarius- Organically Produced Foods document (2007) outlines a small number of substances approved for use in organic agriculture, some of these include;

- Manure, slurry and urine for soil fertilization and conditioning.

- Rotenone, neem, tobacco, copper hydroxide, copper oxychloride, and sulphur for plant pest and disease control [3].

The rejection of synthetic chemicals is one of the main drivers of choice when people choose to buy organically produced foods [4]. And in particular in Ireland, $68 \%$ of respondents to an An Bord Bia survey stated 'Free from chemicals and therefore healthier' when asked what they believe is the main benefit of eating organic foods [5].

Reports suggest that despite the ban on the use of synthetic pesticides in organic farming, organic food products can still contain pesticide residues. Soil, rain, and ground water can all carry these substances to crops growing on organic farms. Environmental conditions such as trees, hedgerows, and nearby conventional farms can all influence the presence of pesticides in organic food products. It is also suggested that the presence of lower levels of pesticides in organic products is not necessarily an advantage as far as food safety is concerned due to the strict control of pesticide levels in conventional produce [6,7]. The study by Gonzalez M, et al. [6] evaluated the levels of lipophilic organochlorine pesticide (e.g. dichlorodiphenyltrichloroethane (DDT), Aldrin, heptachlor) residues in leafy vegetables from 
organic and conventional farms in Argentina. The study found detectable residues in both organic and conventional samples but reported that all levels were below those allowed by the Codex Alimentarius. The study also found that the levels found in organic samples were lower than those found in the conventional samples.

A recent study carried out in Spain using a multi-residue analysis with simultaneous extraction analysed for 90 pesticides, bio-pesticides and mycotoxins (toxins produced by fungi) in organic cereals, cucumbers and wines. The study found pesticide/ bio-pesticide residues (nicotine, epoxiconazole and piperonyl butoxide) in 6 of the 13 cucumber samples. The levels of these compounds ranged from 10.4 to $47.0 \mu \mathrm{g} \mathrm{kg}^{-1}$ [8]. A Portuguese study analysed organic strawberry farms for 14 organochlorine pesticides over two consecutive years (2009-2010). The study found two pesticides, lindane and $\beta$-endosulfan, over the accepted Maximum Residual Limits (MRL's). The researchers also found other pesticides residues below the MRL's (aldrin, o, p'-DDT and methoxychlor) and noted that levels decreased from 2009 to 2010 [9].

Few studies have shown that organic samples are free from pesticide residues, however most do show that fewer residues are found, and at lower levels, when compared to conventional samples. But is this a clear advantage of organic products if the levels found in conventional products are also low in terms of food safety? MRL's are placed on all pesticides used in agriculture and these are strictly controlled by the European Union (active substances), and also at a state level (pesticide products). The United Kingdom Pesticides Residue Committee (2007) measured 220 organic samples in 2006 and found no MRL violations, whereas $1.8 \%$ of the 3342 conventional samples tested were in violation of the limits [10]. In these cases where there is a higher chance, albeit a small chance, of consuming products that contain pesticide residues above the MRL, organic products are more appealing. Organic samples are perceived by many consumers as being 'free' from chemicals, should consumers be aware that this is not always the case? Does 'no added chemicals' necessarily mean no chemicals will be present in the case of fruits and vegetables? To date, there are no published studies that have compared the levels of pesticides in organic and conventional fruits and vegetables on the Irish market.

\section{Experimental-Instrumentation}

\section{Liquid Chromotography/Tandem Mass Spectrometry}

An Agilent 6490 LC-Triple Quadrupole (QQQ) in MS/MS mode was used for the analysis of 319 pesticide residues. Separation was carried out through an Agilent Poroshell C18 2.7 $\mu \mathrm{m} 21 \times 150 \mathrm{~mm}$ column using a gradient mobile phase system of $5 \mathrm{mmol}$ ammonium formate in ultra pure water (A) and $5 \mathrm{mmol}$ ammonium formate in methanol (B). The flow rate was $0.4 \mathrm{ml} /$ min and separation was carried out in 20 minutes as follows; 0.8 min, 40\% B; 3.5 min, 40\% B; 5.0 min, 60\% B; 6.0 min, 60\% B; 12 $\min , 65 \%$ B; $17 \mathrm{~min}, 100 \%$ B; $20 \mathrm{~min}, 100 \% \mathrm{~B}$.

MS/MS detection was carried out in both positive and negative electron ionization (EI) modes depending on the residues included in the method (2 separate sets of standards were prepared). The source parameters for detection were as follows: capillary voltage $3.5 \mathrm{kV}$ (positive) and $2.5 \mathrm{kV}$ (negative); nozzle voltage, $300 \mathrm{~V}$ (positive), $0 \mathrm{~V}$ (negative); desolvation gas (nitrogen) temperature, $120^{\circ} \mathrm{C}$ and flow rate $20 \mathrm{ml} / \mathrm{min}$; sheath gas temperature, $350^{\circ} \mathrm{C}$ and flow rate $12 \mathrm{ml} / \mathrm{min}$; and the nebulizer pressure was 35 psi. Data processing was carried out using Agilent Mass Hunter Quantitative software.

\section{Gas Chromotography/Tandem Mass Spectrometry}

GC-MS/MS analysis of 146 pesticide residues was carried out using an Agilent 7000 Triple Quadrupole (QQQ) system. The GC was operated in pulsed splitless mode at a flow rate of $3 \mathrm{ml} / \mathrm{min}$ and the column was an Agilent HP-5MS $5 \%$ Phenyl Methyl Silox ( $30 \mathrm{~m} \times 250 \mu \mathrm{m} \times 0.25 \mu \mathrm{m})$. The oven temperature program was: $70^{\circ} \mathrm{C}$ held for 2 mins, $25^{\circ} \mathrm{C} / \mathrm{min}$ to $150^{\circ} \mathrm{C}$ for 0 min, the $3^{\circ} \mathrm{C} /$ $\min$ to $200^{\circ} \mathrm{C}$ for $0 \mathrm{~min}$, then $8^{\circ} \mathrm{C} / \mathrm{min}$ to $280^{\circ} \mathrm{C}$ for $10 \mathrm{~min}$. The MS/MS section was operated in a positive ionization mode and all other MS parameters were the same as for the LC/MS/MS. Data processing was also carried out using Agilent Mass Hunter Quantitative software.

Confirmation by Tandem Mass Specrometry: The minimum requirements for the confirmation of a given pesticide were a) a retention time (RT) match with an offset of less than $0.03 \mathrm{~min}$ with respect to a standard from the same run. And b) a second transition ion peak (at the same RT) with a ratio relative to the parent ion peak within the qualifying range; $>50 \%$ ratio with $10 \%$ tolerance, $30-50 \%$ with $20 \%$ tolerance, $10-30 \%$ with $30 \%$ tolerance, and $<10 \%$ with $50 \%$ tolerance.

Quantification by Tandem Mass Spectrometry: Quantification of a given pesticide was calculated from a 5 point calibration curve in duplicate with a minimum $r_{2}$ value of 0.95 for LC-MS/MS and 0.98 for GC-MS/MS. The range of quantification for the GC-MS/MS was 10 to $250 \mathrm{ng} / \mathrm{ml}$, and the range for the LC-MS/MS was 0.5 to $12.5 \mathrm{ng} / \mathrm{ml}$. Pesticides positively detected but present below the $\mathrm{LOQ}$ for the method are reported as trace.

\section{Sampling}

Nine different fruits and vegetables popular to the Irish market were selected for the study namely; apple, banana, broccoli, carrot, cherry tomato, onion, orange, potato and vine tomato. The sampling plan was constructed using survey data of Irish consumers on organic food purchasing habits where a large majority of survey takers stated that they visit large supermarkets for their organic produce along with general purchases [11]. Therefore samples were sourced mainly from large supermarkets from March to September 2011. All samples were purchased no more than 24 hours before preparation.

Sample Preparation: All samples in batches were washed, inedible parts removed (peeled if necessary) and chopped into small cubes. The cubes were mixed and approximately 300 g representative sample was blended using a Hitachi BLN1 household blender until a uniform paste was achieved (duration depended on the nature of the sample). After blending, $100 \mathrm{~g}$ of the sample was accurately weighed into a $200 \mathrm{ml}$ freeze drying 
Table 1: The results of the analysis of 465 pesticide residues in organic and conventional samples including country of origin, pesticide name, mode of action, retention time and concentration. Org = Organic, Conv = Conventional.

\begin{tabular}{|c|c|c|c|c|c|c|c|}
\hline Sample & $\begin{array}{c}\text { Country of } \\
\text { Origin }\end{array}$ & Compound & Type of pesticide & RT & Conc ng/g & Analysis & MRL ng/g \\
\hline apple 1 org & N.Zealand & thiabendazole & fungicide & 4.95 & trace & LCMS & 5000.00 \\
\hline apple 2 org & Chile & clear & & & & & \\
\hline apple 3 org & N.Zealand & clear & & & & & \\
\hline apple 4 conv & N.Zealand & clear & & & & & \\
\hline \multirow[t]{2}{*}{ apple 5 conv } & N.Zealand & myclobutanil & fungicide & 9.59 & trace & LCMS & 500.00 \\
\hline & & fluazinam & fungicide & 15.77 & trace & LCMS & 300.00 \\
\hline \multirow[t]{5}{*}{ apple 6 conv } & Chile & thiabendazole & fungicide & 4.95 & trace & LCMS & 5000.00 \\
\hline & & chlorantraniliprole & insecticide & 7.67 & trace & LCMS & 500.00 \\
\hline & & methoxyfenozide & insecticide & 9.34 & trace & LCMS & 2000.00 \\
\hline & & pyriproxifen & insecticide & 16.12 & trace & LCMS & 200.00 \\
\hline & & diphenylamine & $\begin{array}{c}\text { growth regulator/ } \\
\text { protection in cold storage }\end{array}$ & 10.48 & 20.79 & GCMS & $\begin{array}{l}5000.00 \text { not } \\
\text { approved }\end{array}$ \\
\hline \multirow[t]{6}{*}{ banana 1 org } & $\begin{array}{l}\text { Dominican } \\
\text { Rep. }\end{array}$ & fenpyroximate & insecticide & 16.74 & trace & LCMS & 50.00 \\
\hline & & clofentezine & insecticide & 14.10 & trace & LCMS & 2000.00 \\
\hline & & pirimiphos-ethyl & insecticide & 15.91 & trace & LCMS & $\begin{array}{l}\text { No toxicological } \\
\text { info. Default } \\
\text { MRL } 10.00\end{array}$ \\
\hline & & ethion & insecticide & 16.07 & trace & LCMS & $\begin{array}{l}10.00 \text { (Not } \\
\text { approved) }\end{array}$ \\
\hline & & pyripoxifen & insecticide & 16.12 & trace & LCMS & 200.00 \\
\hline & & propargite & insecticide & 16.53 & trace & LCMS & 10.00 \\
\hline banana 2 org & $\begin{array}{l}\text { Dominican } \\
\text { Rep. }\end{array}$ & clear & & & & & \\
\hline banana 3 org & Peru & clear & & & & & \\
\hline banana 4 conv & Belize & clear & & & & & \\
\hline \multirow[t]{2}{*}{ banana 5 conv } & Costa Rica & thiabendazole & fungicide & 4.94 & trace & LCMS & 5000.00 \\
\hline & & azoxystrobin & fungicide & 8.25 & trace & LCMS & 2000.00 \\
\hline banana 6 conv & None Stated & azoxystrobin & fungicide & 8.25 & trace & LCMS & 2000.00 \\
\hline \multirow[t]{2}{*}{ broccoli 1 org } & Holland & metamitron & herbicide & 2.95 & trace & LCMS & 100.00 \\
\hline & & thiabendazole & fungicide & 4.49 & trace & LCMS & 5000.00 \\
\hline \multirow[t]{3}{*}{ broccoli 2 org } & Holland & metamitron & herbicide & 2.95 & trace & LCMS & 100.00 \\
\hline & & thiabendazole & fungicide & 4.50 & trace & LCMS & 5000.00 \\
\hline & & dodine & fungicide & 14.1 & trace & LCMS & 200.00 \\
\hline \multirow[t]{4}{*}{ broccoli 3 org } & Holland & metamitron & herbicide & 2.94 & trace & LCMS & 100.00 \\
\hline & & thiabendazole & fungicide & 4.49 & trace & LCMS & 5000.00 \\
\hline & & spinosyn A & insecticide & 16.88 & trace & LCMS & 2000.00 \\
\hline & & spinosyn D & insecticide & 17.22 & trace & LCMS & 2000.00 \\
\hline \multirow[t]{2}{*}{ broccoli 4 conv } & U.K & metamitron & herbicide & 2.94 & trace & LCMS & 100.00 \\
\hline & & thiabendazole & fungicide & 4.49 & trace & LCMS & 5000.00 \\
\hline \multirow[t]{2}{*}{ broccoli 5 conv } & Ireland & metamitron & herbicide & 2.94 & trace & LCMS & 100.00 \\
\hline & & thiabendazole & fungicide & 4.49 & trace & LCMS & 5000.00 \\
\hline \multirow[t]{3}{*}{ broccoli 6 conv } & Ireland & metamitron & herbicide & 2.94 & trace & LCMS & 100.00 \\
\hline & & thiabendazole & fungicide & 4.48 & trace & LCMS & 5000.00 \\
\hline & & imazalil & fungicide & 11.76 & trace & LCMS & 50.00 \\
\hline carrot 1 org & Scotland & thiabendazole & fungicide & 4.50 & trace & LCMS & 50.00 \\
\hline carrot 2 org & Scotland & thiabendazole & fungicide & 4.51 & trace & LCMS & 50.00 \\
\hline carrot 3 org & Ireland & thiabendazole & fungicide & 4.49 & trace & LCMS & 50.00 \\
\hline carrot 4 conv & Ireland & thiabendazole & fungicide & 4.49 & trace & LCMS & 50.00 \\
\hline carrot 5 conv & Ireland & thiabendazole & fungicide & 4.50 & trace & LCMS & 50.00 \\
\hline carrot 6 conv & Spain & thiabendazole & fungicide & 4.49 & trace & LCMS & 50.00 \\
\hline
\end{tabular}


Detection of Pesticide Residues in Organic and Conventional Fruits and Vegetables Available in Ireland Using Gas Chromotography/Tandem Mass Spectrometry (GC-MS/ MS) and Liquid Chromotography/Tandem Mass Spectrometry (LC-MS/MS) Detection

\begin{tabular}{|c|c|c|c|c|c|c|c|}
\hline & & linuron & herbicide & 7.71 & 75.27 & LCMS & 200.00 \\
\hline & & imazalil & fungicide & 11.77 & trace & LCMS & \\
\hline cherry $\mathrm{T} 1$ org & Spain & clear & & & trace & & \\
\hline cherry $\mathrm{T} 2$ org & Holland & clear & & & & & \\
\hline cherry T 3 org & Italy & clear & & & & & \\
\hline \multirow[t]{3}{*}{ cherry T 4 conv } & Ireland & propamocarb & fungicide & 1.97 & trace & LCMS & $10,000.00$ \\
\hline & & cyprodinil & fungicide & 11.72 & 68.17 & LCMS & 1000.00 \\
\hline & & fludioxonil & fungicide & 8.19 & 31.95 & LCMS & 1000.00 \\
\hline cherry T 5 conv & Ireland & clear & & & & & \\
\hline cherry T 6 conv & Holland & clear & & & & & \\
\hline onion 1 org & Holland & imazalil & fungicide & 11.78 & 11.13 & LCMS & 50.00 \\
\hline onion 2 org & Holland & clear & & & & & \\
\hline onion 3 org & Argentina & clear & & & & & \\
\hline onion 4 conv & Holland & clear & & & & & \\
\hline onion 5 conv & U.K. & clear & & & & & \\
\hline onion 6 conv & Argentina & clear & & & & & \\
\hline orange 1 org & S. Africa & thiabendazole & fungicide & 4.52 & trace & LCMS & 5000.00 \\
\hline orange 2 org & S. Africa & thiabendazole & fungicide & 4.53 & trace & LCMS & 5000.00 \\
\hline \multirow[t]{2}{*}{ orange 3 org } & S. Africa & thiabendazole & fungicide & 4.52 & trace & LCMS & 5000.00 \\
\hline & & imazalil & fungicide & 11.82 & trace & LCMS & 5000.00 \\
\hline \multirow[t]{2}{*}{ orange 4 conv } & S. Africa & thiabendazole & fungicide & 4.52 & trace & LCMS & 5000.00 \\
\hline & & imazalil & fungicide & 11.81 & 18.87 & LCMS & 5000.00 \\
\hline \multirow[t]{5}{*}{ orange 5 conv } & S. Africa & imidacloprid & insecticide & 2.55 & trace & LCMS & 1000.00 \\
\hline & & carbendazim & fungicide & 3.50 & trace & LCMS & 200.00 \\
\hline & & thiabendazole & fungicide & 4.53 & trace & LCMS & 5000.00 \\
\hline & & pyrimethanil & fungicide & 7.88 & trace & LCMS & $10,000.00$ \\
\hline & & imazalil & fungicide & 11.83 & trace & LCMS & 5000.00 \\
\hline \multirow[t]{5}{*}{ orange 6 conv } & S. Africa & imidacloprid & insecticide & 2.55 & trace & LCMS & 1000.00 \\
\hline & & carbendazim & fungicide & 3.50 & trace & LCMS & 200.00 \\
\hline & & thiabendazole & fungicide & 4.52 & 31.60 & LCMS & 5000.00 \\
\hline & & pyrimethanil & fungicide & 7.88 & trace & LCMS & $10,000.00$ \\
\hline & & imazalil & fungicide & 11.84 & 63.24 & LCMS & 5000.00 \\
\hline \multirow[t]{3}{*}{ potato 1 org } & Israel & pencycuron & fungicide & 14.25 & trace & LCMS & 100.00 \\
\hline & & 3-chloroaniline & herbicide & 5.48 & trace & GCMS & Not listed \\
\hline & & chlorpropham & herbicide & 11.05 & trace & GCMS & $10,00.00$ \\
\hline potato 2 org & Israel & clear & & & & & \\
\hline potato 3 org & Israel & clear & & & & & \\
\hline potato 4 conv & Ireland & pencycuron & fungicide & 14.24 & trace & LCMS & 100.00 \\
\hline potato 5 conv & Ireland & clear & & & & & \\
\hline potato 6 conv & N. Ireland & clear & & & & & \\
\hline vine $\mathrm{T} 1$ org & Holland & clear & & & & & \\
\hline vine $\mathrm{T} 2$ org & Italy & chlorpyriphos & insecticide & 15.96 & trace & LCMS & 500.00 \\
\hline vine T 3 org & Holland & iprodione & fungicide & 28.44 & trace & GCMS & 5000.00 \\
\hline vine $\mathrm{T} 4 \mathrm{conv}$ & Ireland & clear & & & & & \\
\hline \multirow[t]{3}{*}{ vine T 5 conv } & Ireland & propamocarb & fungicide & 1.98 & 9.84 & LCMS & $10,000.00$ \\
\hline & & cyprodinil & fungicide & 11.71 & trace & LCMS & 1000.00 \\
\hline & & chlorothalonil & fungicide & 14.82 & 98.29 & GCMS & 2000.00 \\
\hline \multirow[t]{4}{*}{ vine T 6 conv } & Ireland & propamocarb & fungicide & 1.99 & 11.70 & LCMS & $10,000.00$ \\
\hline & & fludioxonil & fungicide & 8.18 & 14.51 & LCMS & 1000.00 \\
\hline & & cyprodinil & fungicide & 11.71 & trace & LCMS & 1000.00 \\
\hline & & chlorothalonil & fungicide & 14.82 & 154.07 & GCMS & 2000.00 \\
\hline
\end{tabular}

Note: Bolded compounds are those measured to be in the quantifiable range of the particular method used. 
container, the sample was shell frozen in a Lab Conco Shell Freezer at $-42 \mathrm{C}$ and stored at $-80^{\circ} \mathrm{C}$. Samples were then freeze-dried using a Thermo Heto PowerDry LL300 freeze dryer, the duration of which was also dependent on the nature of the sample. When fully dried, the samples were weighed, ground to a fine powder using a mortar and pestle and stored in sterile plastic tubes at $-20^{\circ} \mathrm{C}$ in the dark. It is important to note for the purpose of this study that, apart from cooking, all samples were prepared as if being consumed before the drying process. Therefore pesticide residues detected should represent those present in the food eaten by a consumer and not simply on a whole sample.

Sample Extraction: Samples were extracted using a Mini Luke multi-residue solvent extraction according to The Ministry of Public Health, Welfare and Sport, Analytical Methods for Pesticide Analysis, $6^{\text {th }}$ Edition (1996) [12]. In summary, $1.5 \mathrm{~g}$ of dried sample was added to $30 \mathrm{ml}$ of acetone, dichloromethane and petroleum ether ( $90 \mathrm{ml}$ total) and homogenised using an Ultra Turrax IKA digital homogeniser. $60 \mathrm{ml}$ of this mixture was evaporated to near dryness (volume circa. $2 \mathrm{ml}$ ) using a Büchi Rotavapor R-205 and reconstituted in $10 \mathrm{ml}$ of ethyl acetate, this gave each extract a concentration of $1 \mathrm{~g} / \mathrm{ml}$. The samples were then filtered through $0.2 \mu \mathrm{m}$ syringe filters and transferred to amber vials. Samples for analysis by LC-MS/MS were diluted 1:20 before transfer to vials by adding $0.5 \mathrm{ml}$ of the filtered sample in ethyl acetate to a volumetric flask and making up to $10 \mathrm{ml}$ with methanol. This dilution was accounted for at the data acquisition.

\section{Results and Discussion}

The results of the analysis of 465 pesticide residues using GC/ MS/MS and LC/MS/MS are shown in Table 1. In total, 54 samples were included in the study, 27 of these were organic, and 27 were conventional.

Of the 27 organic samples, 15 contained one or more pesticide residues. Cherry tomatoes were the only group of the organic samples that were clear from any pesticide residue. One of pesticide residues detected was present at a quantifiable level ( $>0.5 \mathrm{ng} / \mathrm{g}$ ), imazalil (Figure 1) found in an organic onion sample was measured to have a concentration of $11.13 \mathrm{ng} / \mathrm{g}$, but was below the MRL at $50 \mathrm{ng} / \mathrm{g}$. A total of 29 residues were found across the organic samples.

Of the 27 conventional samples tested, 17 contained one or more residues. Twelve of the pesticides identified were present above the LOQ. These were; diphenylamine (Figure 2) found in apple (20.78 ng/g); linuron found in carrot $(75.27 \mathrm{ng} / \mathrm{g})$; fludioxonil and cyprodinil found in the same cherry tomato sample (68.17 and $31.95 \mathrm{ng} / \mathrm{g}$ respectively); imazalil in orange

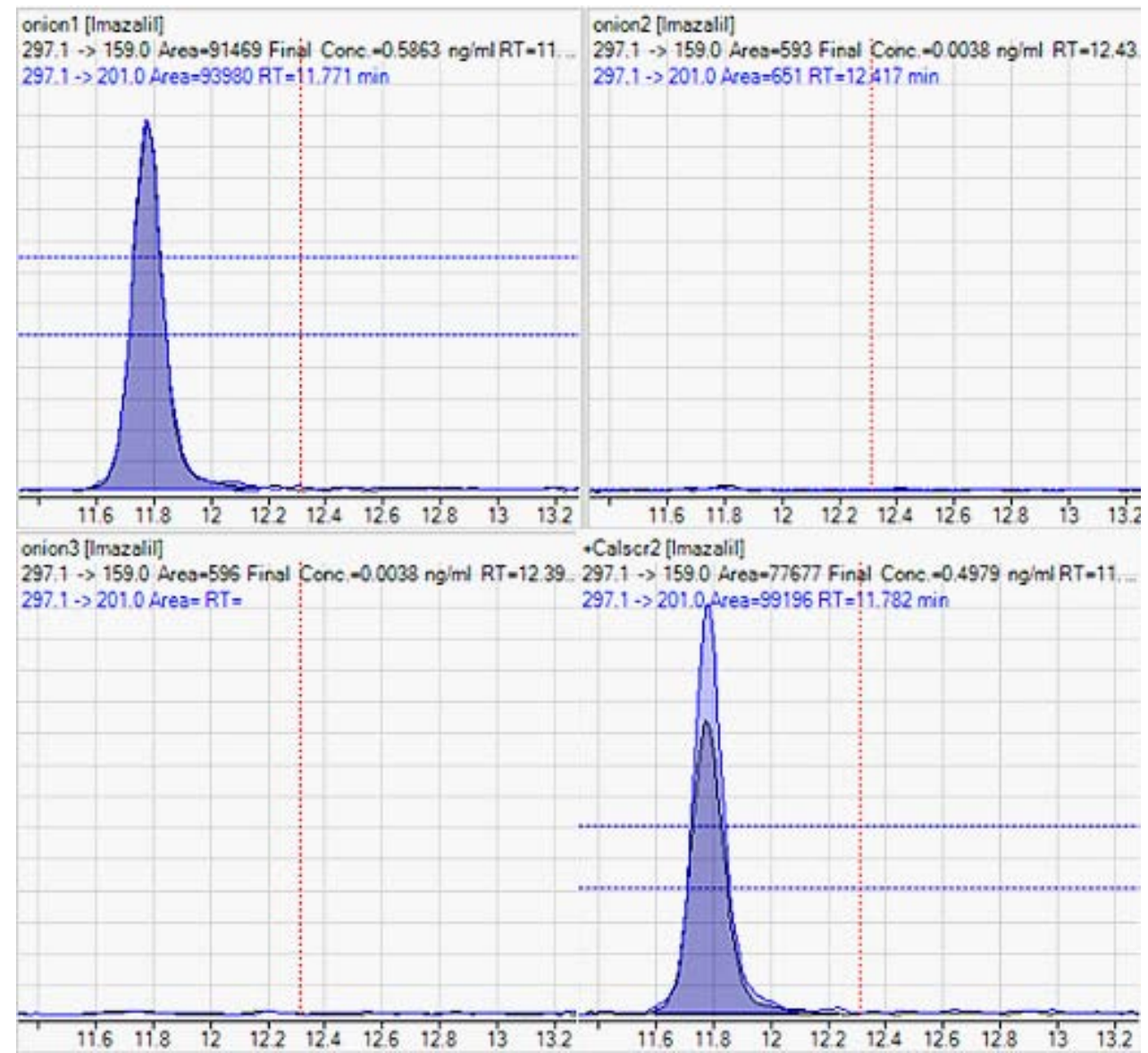

Figure 1: Imazalil peak at detection step in organic onion sample 1 (diluted by a factor of 20), compared to peak from screener mix prepared at concentration of lowest calibration standard (bottom peak) and other organic samples analysed in the same batch. 


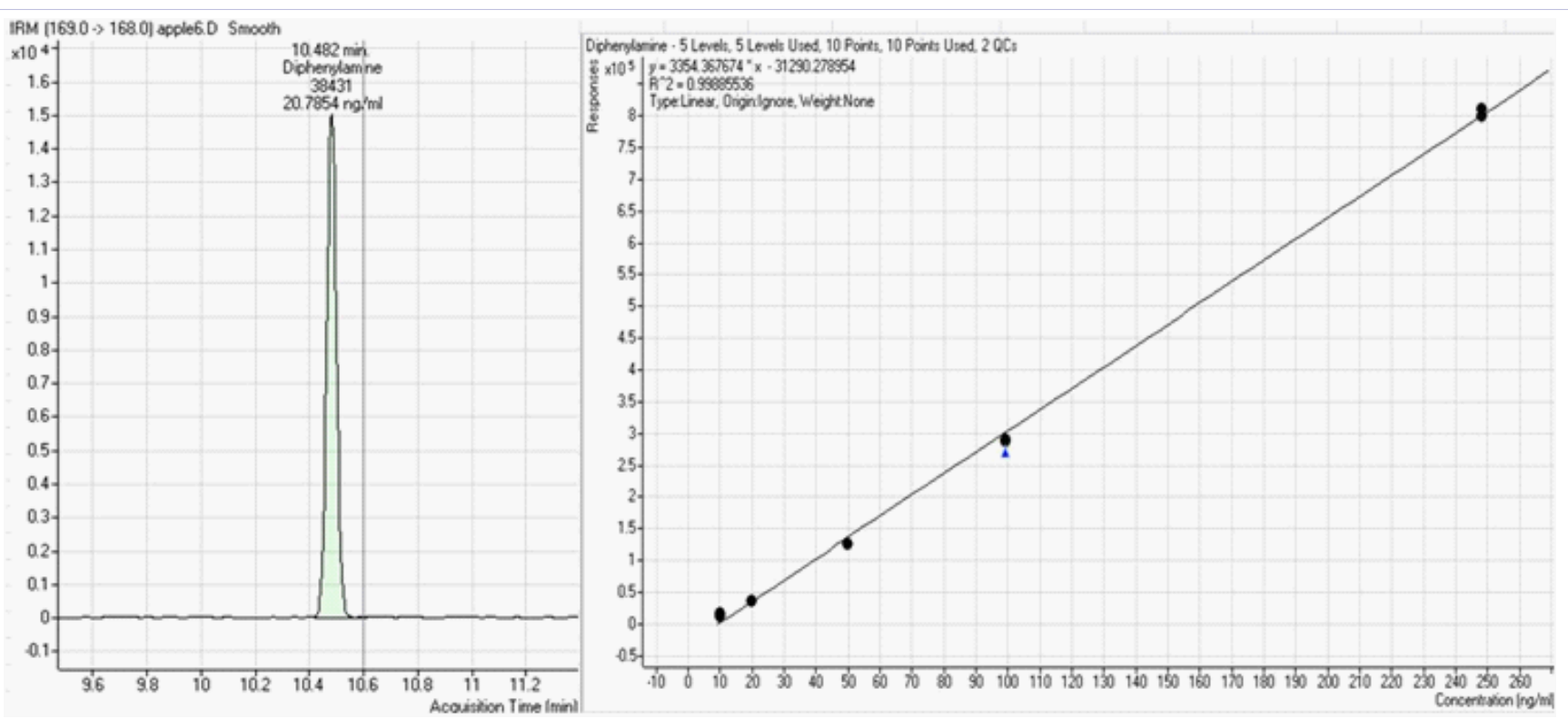

Figure 2: Diphenylamine peak at quantification step detected in apple 6 (conventional) by gas chromotography/tandem mass spectrometry with standard curve.

(peel removed) (18.87 ng/g); thiabendazole and imazalil in a second orange sample (31.60 and $63.24 \mathrm{ng} / \mathrm{g}$ ); propamocarb (9.84 and $11.70 \mathrm{ng} / \mathrm{g}$ ) and chlorothalonil (98.29 and $154.07 \mathrm{ng} / \mathrm{g}$ ) in two of the vine tomato samples and fludioxonil in another vine tomato sample $(14.51 \mathrm{ng} / \mathrm{g})$. In total, 43 residues were found in the 27 conventional sample batches.

The sample with the largest amount of detectable residues, six, was an organic banana sample, and this refers to the pulp of the banana only. This result shows that pesticide residues are not a food surface issue that can be rinsed off before eating. Residues can be found within a fruit and uptake from soil is possible even when organically grown. Broccoli and oranges both contained the most detectable residues as food groups. Across the 6 samples in each group, 16 residues were detected in broccoli and oranges. This may show that more pesticides are applied to these foods in agriculture, or that the uptake of pesticides is significant/the surface of the food is more conducive to holding residues.

The MRL is cited for each pesticide quantified in the method in Table 2. Each limit is specific for the food type and is cited from the current EU Pesticides database updated on the 02/05/2013 under the Regulation (EC) No. 1107/2009. None of the pesticides quantified were above the MRL's [13].

In terms of food safety this study cannot show that organic products are a safer choice in terms of human health compared to their conventional counterparts. In agreement with the review by Tobin R, et al. [14], it is not correct to promote organic foods on the basis that the chemicals found in conventional agriculture (and as proven in this study, in organic) present a serious health risk at the levels commonly found in the food we eat. It is also noted in the review of the Irish organic food market that consumers may choose organic products not for food safety, but because the non-use of pesticides supports animal welfare, biodiversity
Table 2: A summary of the results

\begin{tabular}{|l|c|c|}
\hline & $\begin{array}{c}\text { Organic } \\
(\mathbf{n = 2 7 )}\end{array}$ & $\begin{array}{c}\text { Conventional } \\
(\mathbf{n = 2 7})\end{array}$ \\
\hline $\begin{array}{l}\text { No. of samples containing detectable } \\
\text { residues }\end{array}$ & 15 & 17 \\
\hline No. of total residues (>LOQ) & $29(1)$ & $43(13)$ \\
\hline $\begin{array}{l}\text { Concentration range of residues } \\
\text { quantified }\end{array}$ & $11.13 \mathrm{ng} / \mathrm{g}$ & $9.84-154.07 \mathrm{ng} / \mathrm{g}$ \\
\hline
\end{tabular}

and soil health [14]. Studies have also noted the prevalence of other contaminants, in particular natural contaminants such as mycotoxins and pathogenic bacteria in organic foods and these should be taken in to consideration in any comparison of the safety of these two types of food propagation [4,7]. Pussemier L, et al. [7] states that natural toxicants need to be better identified in organic production and studies by Oliveira M, et al. [15] and Weißner et al. [16] have measured higher levels, albeit safe levels, of pathogenic bacteria in organic foods $[7,15,16]$.

\section{Conclusion}

A similar number of organic (15) and conventional (17) samples tested positive for detectable residues, however the number of residues detected was higher in conventional (43) than in organic (29), and the concentration of these residues were significantly higher. This result is in agreement with the previous study by Gonzalez M, et al. [6]. Table 2 summarises the results of the study.

The study concludes that both organic and conventional fruits and vegetables purchased from Irish supermarkets may contain pesticide residues and it cannot be said that organic products are void of these compounds because they are not physically applied in organic agricultural practices. However the level of exposure to these compounds from organic products may be significantly 
lower. But does this form a particular advantage from a health perspective given that none of the pesticides measured were above, or close to the MRL's applied under EU regulation? And hence are organic fruits and vegetables truly distinguishable from conventional products in terms of the presence of pesticides when comparing the final food product?

\section{Acknowledgements}

This study was kindly facilitated and funded by the Pesticide Control Service Laboratory at The Irish Department of Agriculture, Food and Marine, Co. Kildare, Ireland. All credit for the development and validation of the methods used goes to the team at this facility. This study is part of a project funded by the Irish Research Council.

\section{References}

1. Rathore HS, Nollet LML (2012) Pesticides: evaluation of environmental pollution. Taylor \& Francis CRC Press, Boca Raton, Florida, USA.

2. World Health Organization (WHO) (2010) The WHO recommended classification of pesticides by hazard and guidelines to classification 2009. WHO Press, Geneva, Switzerland.

3. WHO \& FAO (2007) Organically produced foods ( $3^{\text {rd }}$ Edn)., Codex Alimentarius Commission, Rome, Italy, p. 31-35.

4. Trewavas A (2004) A critical assessment of organic farming-andfood assertions with particular respect to the UK and the potential environmental benefits of no-till agriculture. Crop Project 23(9): 757 781.

5. BordBia (2011) Market Potential for Organic Food \& Irish Consumer Expectations.

6. Gonzalez M, Miglioranza KSB, Aizpul de Moreno JE, Moreno VJ (2005) Evaluation of conventionally and organically produced vegetables for high lipophillic organochlorine pesticide (OPC) residues. Food Chem Toxicol 43(2): 261-269.
7. Pussemier L, Larondelle Y, Van Peteghem C, Huyghebaert A (2006) Chemical safety of conventionally and organically produced foodstuffs: A tentative comparison under Belgian conditions. Food Control 17(1): 14-21.

8. Gonzalez RR, Garrido Frenich A, Martinez Vidal JL, Prestes OD, Grio SL (2011) Simultaneous determination of pesticides, biopesticides and mycotoxins in organic products applying a quick, easy, cheap, effective, rugged and safe extraction procedure and ultra-high performance liquid chromatography-tandem mass spectrometry. J Chromatogr A 1218(11): 1477-1485.

9. Fernandez VC, Domingues VF, Mateus N, Delerue-Matos C (2011) Organochlorine pesticide residues in strawberries from integrated pest management and organic farming. J Agric Food Chem 59(14): 7582-7591.

10. Pesticide Residue Committee (2007) Annual report of the pesticide residues committee. Department for Environment, Food and Rural Affairs, UK.

11. BordBia (2008) How Modern Irish Consumers View Organic Food.

12. Ministry of Public Health (1996) Welfare and Sport, The Netherlands. Analytical Methods for Pesticide Analysis (6 $\left.{ }^{\text {th }} \mathrm{Edn}\right)$.

13. European Communities (2013) EU Pesticides database, active substances MRL's (2009).

14. Tobin R, Larkin T, Moane S (2011) The Irish organic food market, shortfalls, opportunities and the need for research. J Sci Food Agr 91(12): 2126-2131.

15. Oliveira M, Usall J, Vinas M, Anguera M, Gatius F, et al. (2010) Microbiological quality of fresh lettuce from organic and conventional production. Food Microbiol 27(5): 679-684.

16. Wießner S, Theil B, Kramer J, Kopke U (2009) Hygienic quality of head lettuce: effects of organic and mineral fertilisers. Food Control 20(10): 881-886. 